\title{
The end of the age of Aquarius?
}

Concerns about energy and inflation, linked to a conservative trend in US politics, are beginning to eclipse the moral commitment to a clean and safe environment characteristic of the past decade. In the first of three articles on how this has happened and what may follow, David Dickson describes how the energy issue has become a major threat to US environmental movements.

"Man can survive pollution; environmentalists can relax about that. The question is whether he can survive regulation." These words headed a fullpage advertisement in the US national press last week for a new book, Restoring the American Dream, by best-selling author Robert J Ringer.

The sentiments are not new. Indeed such arguments have been frequently heard since concerns about the effects of pesticides on bird-life ushered in the environmental movement in the mid-1960s. And they have provided a constant back-drop to a decade of legislative measures designed to protect the US environment against the worst excesses of technological growth.

In the past few months, however, concerns about growing inflation and the security of future energy supplies have both helped to generate an anti-regulation bandwagon that is demanding a major rethink of this legislation and its effects - as well as laying the ground-work for a substantially different approach to environmental regulation in the 1980s.

As far as the administration is concerned, this will mean less emphasis on the government as a regulator of industrial activity, and greater emphasis on the market-place as the matrix for 'rational' decision-making on regulatory activities.

For the environmental movement, it means a shift from the essentially defensive posture which the movement has been adopting in recent years, capitalising on the gains made earlier in the decade, to one in which urgent action is now needed in most fields (except perhaps that of nuclear energy) to prevent the threat of a complete rout.

Two main factors have fuelled this antiregulatory tendency. The first has been the argument that inflationary problems are directly linked to a decline in national productivity (which fell by an annual equivalent rate of 5.9 per cent in the second quarter of 1979); and that this is largely linked to a decline in technological

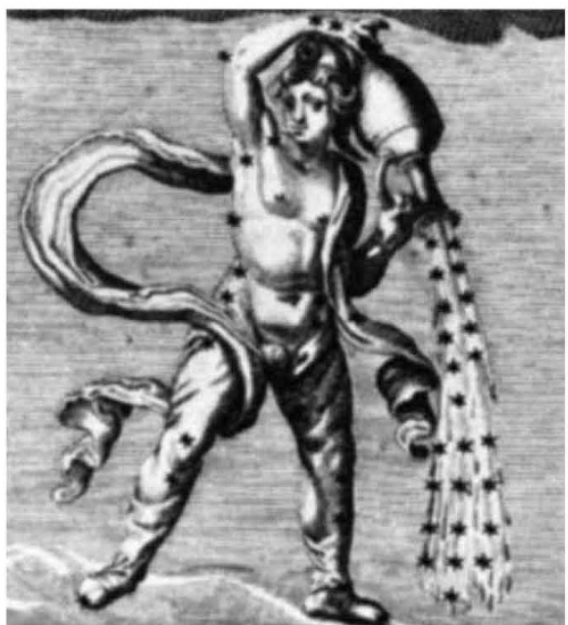

certain aspects of clean air legislation. For example, many power companies are being squeezed between new limits on sulphur dioxide emissions, and the president's call to reduce oil consumption by half by 1990 , largely through the use of coal; and costbenefit analysis is being used as a prime tool to tackle such conflicts.

In the past few months, however, this approach has been overtaken by a more overtly political drive aimed at circumscribing the government's role in a range of activities. One of the first manifestations of this trend was California's decision last year to halve its property taxes, the famous Proposition 13; more recently, government regulators have become a prime target for political abuse.

According to a survey published in innovation, itself due partly to increased environmental and health regulation.

"What started as a regulatory snowball ten years ago has become an avalanche, and innovation is one of its victims, " $\mathrm{Dr} \mathrm{H}$ D Doan, ex-president of the Dow Chemical Company, said at a meeting of the American Chemical Society in Washington last week. "George Orwell may not have been accurate in his predictions; but the regulators tend to confirm his foresight."

The second factor which has played a key role is the pressure on US politicians, following the Iranian oil crisis earlier this year, to be seen to be doing something about guaranteeing future energy supplies - if necessary at the expense of environmental considerations.

Two developments in particular have led to a qualitative rise in the energy versus environment debate. The first has been the push for a massive programme to stimulate the production of synthetic fuels as a substitute for imported oil, and the renewed emphasis on the use of coal, both of which,if not properly handled, could have a significant impact on factors such as the build-up of atmospheric $\mathrm{CO}_{2}$.

The second factor, which many environmentalists fear could be even more damaging, is the president's decision to establish a top-level Energy Mobilisation Board. Of particular concern are the strong powers which many congressmen would like this board to have to over-ride federal and state environmental legislation in order to speed up major energy programmes.

The idea that there are necessary tradeoffs between energy demands and environmental considerations is not new. Until relatively recently, however, the administration has sought to contain such debates within a framework of cost-benefit analysis, using economic pay-off as the means of weighing up the merits of one course of action against another.

Such analysis, for example, has been behind some recent decisions to relax
March by Opinion Research Corporation, for example, more than half of the general public feel that the costs of government regulation exceed the benefits. And by a margin of two to one, those interviewed said that there was a need for less rather than more government regulation.

With elections coming up next year, congressmen from both parties are eagerly responding to what they see as popular demands for less regulation - in many cases outstripping the administration's economists in their anti-regulatory fervour. In the last two weeks, for example, this tendency has become clear in four separate congressional actions.

The first was an amendment by Senator Dale Bumpers (Dem. Arkansas) to a bill on the federal court system, requiring a of a particular set of regulations in court every time that they are challenged. The amendment thus challenging the "presumption of validity" that now covers agency rules when challenged in court proceedings, making it easier for courts to overturn federal regulatory decisions.

The second decision was taken during a debate last Tuesday on a strip-mining bill, which would allow states to disregard regulations laid down by the Department of the Interior about making-good disturbed landscape. On the same day, the Senate also voted to allow the completion of the Tellico Dam, thus in effect agreeing to the extinction of the snail darter, whose status as an "endangered species" had previously led to a Supreme Court ruling that the dam should not be finished.

Perhaps the most significant decision, however, was taken by the House Commerce Committee. In discussing the role of the President's proposed Energy Mobilisation Board, the committee agreed that the board should have considerably stronger powers than the president had proposed, enabling it to waive environmental regulations.

Despite intense efforts by environmental federal agency to demonstrate the validity 


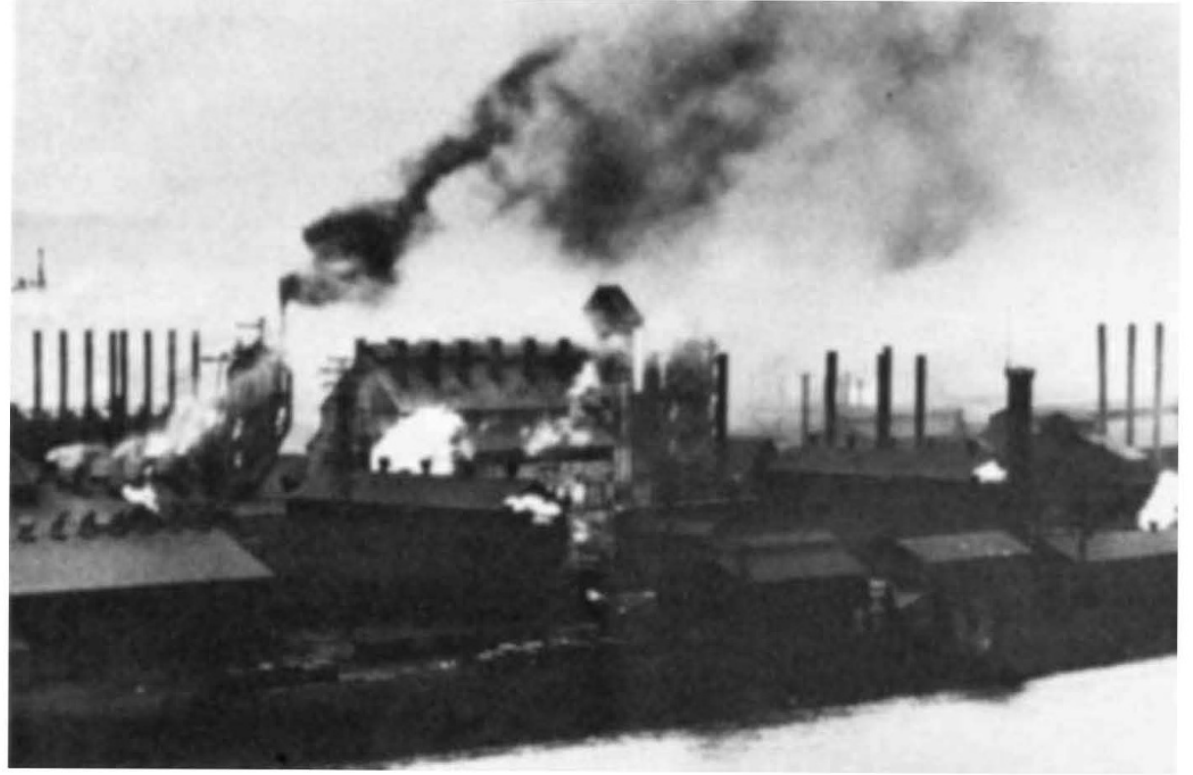

lobbying groups, the committee approved a bill which would allow the board to recommend that the president waive any federal, state or local law blocking a highpriority energy project.

Environmentalists are supporting an alternative version of the bill under which, as originally proposed by the adminstration, the board would be merely able to speed-up procedural aspects of project approval; and one sympathetic congressman, Representative Tim Wirth (Dem. Colorado), has promised a "huge, huge battle" when the Commerce committee bill is debated by the full House.

Critics of the stronger version of the bill have been particularly concerned about the apparent support that this version is now receiving from the White House (even though administration officials claim that their support is at present essentially a bargaining device).

"If we are not careful, the Energy Mobilisation Board could threaten fifteen years of environmental work,"' says David Maselli, energy policy director for Friends of the Earth. He points to the low priority given to environmental considerations in the energy proposals with which President Carter emerged from his recent seclusion at Camp David; "it was close to the bottom line - so close to a 'worst case' guess about the outcome of Carter's deliberations that many environmentalists were genuinenly surprised,' he says.

Maselli points out that environmental groups have not lost out on everything in recent legislative debates. They have had considerable success, for example, in slowing down the projected growth of the administration's proposed programme for synthetic fuels - an issue against which "we are standing as hard as we can" says Herb Epstein of the Solar Lobby - and have won acceptance for numerous solar energy and conservation measures.

But no-one denies that there are some major battles ahead. "I think it is going to be a hellish struggle, even to preserve the gains that we have won," says Epstein. And others are already saying that the 1970 s may be looked back on as "the golden age of environmentalism."

Speaking at the ACS meeting last week, Dr Frank Press, director of the Office of Science and Technology Policy, indicated a shift in administration thinking when he said that he saw a "new philosophy" being pursued. This was one that recognised that the desired goals of environmental, health and safety regulation might best be achieved through incentive-oriented, rather than a direct federal regulation, approach.

"Such an approach, rather than commanding that specific technologies be applied to achieve the specific standards, allows the industry to choose its own paths to achieving the same end results, " he said. And he gave as an example the "bubble approach" which the Environmental Protection Agency had introduced to air pollution, in which a plant can set its own effluent release from each point source as long as the total effluent release complies with a federal standard set for the entire complex.

"One of the important things to recognise regarding this approach to regulation is that it provides new incentives for industry to innovate. It takes some of the repressiveness and uncertainty out of regulation, and relies more on market forces to achieve the desired goals in environmental quality, health and safety."

The need to allow an increased, if not dominant, role for market forces is also emphasised in a report Energy: The Next Twenty Years, sponsored by the Ford Foundation and published in Washington last week by Resources for the Future.

"Air pollution control policy should concentrate on providing incentives for making progress toward cleaner air in a way that is cost-effective over time," says the report, produced by a group of academics and industrialists. Attempts to define rigid "safe" exposure levels are both scientifically and administratively unsound, the report recommends moving towards "a different philosophy" of pollution control, deemphasising rigid deadlines and standards, in which market processes determine the details of ways to meet particular environmental goals.

The new shift is also likely to have an effect on the academic environmental science community. "The new climate for environmental regulation makes the need for accurate scientific data even more important than before; in particular there will be a need for better epidemiological data, looking at the real effects both of pollutants and of environmental regulations," says Dr John E Cantlon of Michigan State University, chairman of the National Academy of Sciences' Environmental Studies Board.

"I do not think that all the census work that I have seen indicates that people are willing to give up clean air or clean water. But they may be more willing than before to ask the question of whether the costeffectiveness level of certain regulations is defensible," says Dr Cantlon.

Finally the environmental movement is beginning to realise that the strategies which it used so successfully in the early 1970s to achieve significant legislative victories may no longer be appropriate for the form of the debate in the 1980s. And that it may be necessary to form new coalitions - particularly with labour or other political groups - if it wants to remain effective.

"One of the weaknesses of the environmental movement is that it has never been able to deal properly with economic issues. But recent moves by the administration on issues such a sythetic fuels mean that the stakes have been raised, and we must deepen both our understanding and our political linkages if we wish to remain effective," says Gail Daneker of Environmentalists for Full Employment.

What effect environmental issues have on next year's presidential election remains to be seen. Certainly many of those who actively supported President Carter earlier in his administration are growing increasingly sceptical. "The one thing worse than having a public figure against you is having a powerful public figure who used to be on your side against you," says David Maselli, referring in particular to the administration's apparent support for a strong Energy Mobilisation Board.

But few see the issue merely in terms of personalities - or of presidential politics. Rather it is a response to an economic and political climate fundamentally different from that which saw the dawning of an "Age of Aquarius" in the late 1960s. With demands for a decreased government role in regulation, and an increased emphasis on market-place economics, moral commitments no longer carry much political capital.

Next week: health and innovation 